\title{
Hot Stamping of Boron Alloy Steels Using Resistance Heating
}

\author{
Zhiqiang Zhang ${ }^{1, \mathrm{a}}$, Xiaofei Jia ${ }^{1, \mathrm{~b}}$, Xiangji $\mathrm{Li}^{2, \mathrm{c}}$, Yong \\ $\mathrm{Zhao}^{2, \mathrm{~d}}$ \\ ${ }^{1}$ School of Material Science and Engineering, Jilin \\ University, Changchun, 130022, China
}

\begin{abstract}
A hot stamping process of boron alloy steel using resistance heating was developed. Relationship between heating time and temperature was investigated. Hardness measurements and microstructural analyses of quenched blanks heated by resistance heating and furnace heating were performed. Miniature tensile specimens were machined from the quenched blanks and tested in tension at $0.01 \mathrm{~s}^{-1}$ stain rate. Temperature measurements showed that it only needed 1.4 seconds to heat the blank to $950^{\circ} \mathrm{C}$ using resistance heating. The resulting stress vs. strain curves showed that the UTS increased from $1496 \mathrm{MPa}$ to $1573 \mathrm{MPa}$ and the elongation increased from $10 \%$ to $16 \%$ for the specimens heated by resistance heating. In contrast to furnace heating, resistance heating produced more refined marensite grains and showed a little higher harness values.
\end{abstract}

Keywords-hot stamping; boron steels; resistance heating; martensite;

\section{INTRODUCTION}

The current demand to reduce vehicle weight for improved fuel efficiency, while maintaining crash performance, has driven the automotive industry to innovative materials and manufacturing processes. The hot stamping process is one such recent innovation that is gaining popularity for the manufacture of vehicle structural components. In hot stamping process, sheet metal is austenized and subsequently formed and quenched in a water-cooled die. During quenching process, the hot blank is quenched within the tool at a cooling rate greater than $30^{\circ} \mathrm{C} / \mathrm{s}$ and the austenitic microstructure transforms into full martensite. Bardelcik et al.[1] developed fully martensitic microstructure has high tensile strength about $1500 \mathrm{MPa}$ and Vickers hardness values in excess of $425 \mathrm{HV}$. Presently, roller hearth furnace is generally used to heat blank. However, the temperature of hot blank will decrease dramatically when it is removed from the furnace to a press. In addition, the blank will be oxidized seriously during the removal after being heated above $900^{\circ} \mathrm{C}$ in the furnace. All these defects of furnace heating show the need for alternative approaches to heat blank.

The resistance heating has a simple heating apparatus which can be put together with a press to avoid removal of hot blank. Heating the blank rapidly and synchronizing with a press. Mori et al. [2,3] developed a warm and hot stamping process of ultra-high strength steel (UHSS) using resistance heating. But the plasticity of the as-quenched part was not discussed. Mori et al. [4-7] improved the quality of

\author{
${ }^{2}$ Roll Forging Research Institute, Jilin University, \\ Changchun, 130022, China \\ azhangzq@jlu.edu.cn, bjiaxiaofei66@163.com, \\ cxjli@jlu.edu.cn, dzhao_yong@jlu.edu.cn
}

sheared edges in punching process of UHSS by means of resistance heating. Zhao et al. [8] applied electropulsing to enhance the mechanical properties of boron steel. The results showed that the steel exhibited unexpected high strength and ductility. Because the blank was quenched by water directly in their researches, the cooling speed of the blank is much higher than that of being quenched by tool which is widely used in industrial production.

In this study, B1500HS boron steel sheet metal was austenized by resistance heating and furnace heating respectively and then quenched with a cold tool to compare the different effects of the two heating approaches on mechanical properties and microstructures of boron steel.

\section{EXPERIMENTAL METHODS}

\section{A. B1500HS boron steel}

B1500HS boron steel with a thickness of $1.5 \mathrm{~mm}$ was used for this study. This sheet metal has no coating and the as-received microstructure of boron steel consists of ferrite/pearlite with a yield strength and ultimate tensile strength of $365 \mathrm{MPa}$ and $520 \mathrm{MPa}$, respectively. Chemical composition of the steel is given in Table 1 .

TABLE 1 CHEMICAL COMPOSITION (WT. \%) OF THE B1500HS BORON STEEL.

\begin{tabular}{lrlllllll}
\hline $\mathrm{C}$ & $\mathrm{Si}$ & $\mathrm{Mn}$ & $\mathrm{P}$ & $\mathrm{S}$ & $\mathrm{Cr}$ & $\mathrm{Ti}$ & $\mathrm{B}$ & $\mathrm{Al}$ \\
\hline 0.2 & 0.4 & 1.2 & 0.02 & 0.015 & 0.25 & 0.04 & 0.002 & 0.04
\end{tabular}

\section{B. Resistance heating}

The sheet metal can be heated by electrical resistance during the electrifying, the so-called Joule heat. The resistance heating is rapid enough to synchronise with a press and has higher energy efficiency and more compact equipment than furnace heating. Resistance heating equipment was used to heat the blank in this study as shown in Figure 1. The equipment has an AC power supply with $7 \mathrm{~V}$ voltage and maximum output current of $2500 \mathrm{~A}$. A thermocouple was welded to the middle surface of the blank to record temperature changes as shown in Figure 2. The time of heating was set at $0.6 \mathrm{~s}, 0.8 \mathrm{~s}, 1.0 \mathrm{~s}, 1.2 \mathrm{~s}, 1.4 \mathrm{~s}$ and $1.6 \mathrm{~s}$ respectively to get corresponding temperature. Then the heated blank was put in air to quantify the temperature drop of blank. 


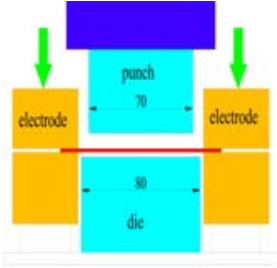

(a) Electrifying

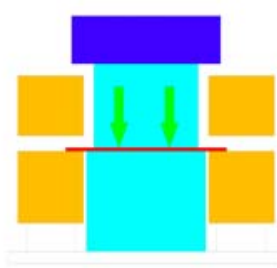

(b) Forming
Figure 1. Resistance heating equipment

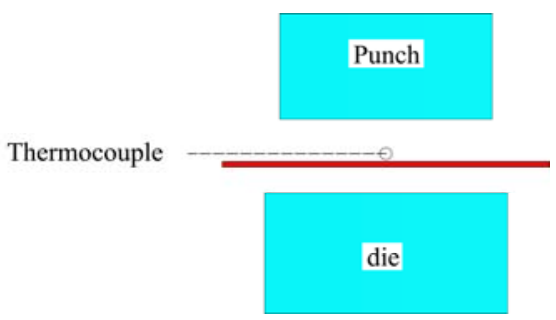

Figure 2. Position of thermocouple.

The blank was clamped between electrodes and electrified from both electrodes. There was $2 \mathrm{~mm}$ gap between the blank and the flat die to avoid heating the die. When the blank was heated up to $950^{\circ} \mathrm{C}$, the electrodes released and the punch pressed down simultaneously and then the blank was quenched in cold flat die and punch. Velocity of the punch was fixed at $200 \mathrm{~mm} / \mathrm{s}$. The quenching pressure was $14.3 \mathrm{MPa}$ and the holding time was $10 \mathrm{~s}$.

\section{Uniaxial tension testing}

Uniaxial tension tests were conducted on specimens that were machined from the quenched blanks which were heated in $950^{\circ} \mathrm{C}$ by resistance heating and furnace heating. Uniaxial tension tests were conducted at $0.01 \mathrm{~s}^{-1}$ stain rate using an INSTRON Series5860 electromechanical testing system. The specimen gauge length was $8 \mathrm{~mm}$.

\section{Hardness testing}

The hardness measurements were made with MH-3 hardness tester using a $200 \mathrm{~g}$ load. The hardness test specimens were cut from the edge of the quenched blanks which were heated by resistance heating and furnace heating. Interval between each test point was $2 \mathrm{~mm}$.

\section{E. Metallography}

Microstructural characterization was carried out using a Zeiss Axio Scope.A1 optical microscope. The specimen were polished to a mirror finish using $\mathrm{SiC}$ paper; followed by 3 and $1 \mu \mathrm{m}$ diamond paste. A $4 \%$ Nital etching solution was used to reveal the microstructure.

\section{RESULTS AND DISCUSSION}

\section{A. Measured temperatures}

We can see that a linear trendline is shown to fit heating time for temperature from Fig. 3. The heating temperature of blank can be controlled by the heating time. It only needed 1.4 seconds to get high temperature of $950^{\circ} \mathrm{C}$. Because of high speed heating, resistance heating can synchronize with a press.

In Fig.4, as the heating temperature increased, the temperature decrease of blank became large. It took at least $5 \mathrm{~s}$ transferring the hot blank from the furnace to the press, while the time for the resistance heating was only $0.5 \mathrm{~s}$. The decrease of temperature in $0.5 \mathrm{~s}$ was within 10 degrees, whereas the decrease in temperature in $5.0 \mathrm{~s}$ was over 80 degrees.

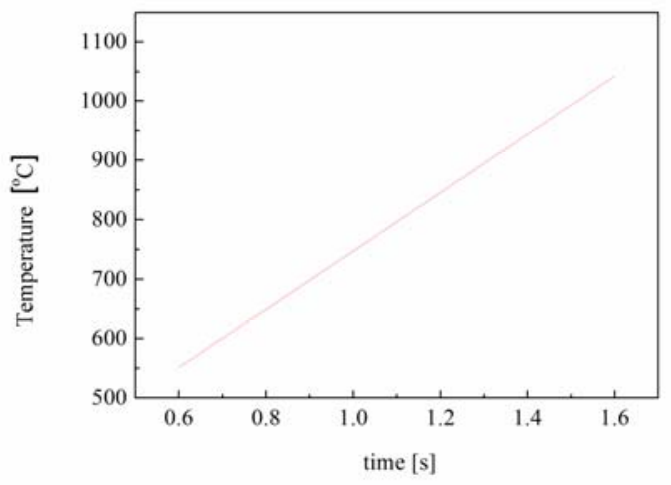

Figure 3. Relationship between temperature and heating time.

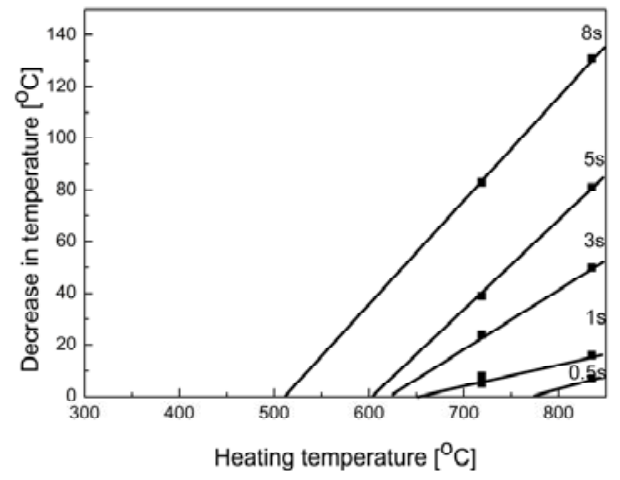

Figure 4. Relationship between temperature decrease of the blank cooling in air and heating temperature for different times.

\section{B. Engineering stress versus strain}

In contrast to furnace heating, resistance heating produced a remarkable increase in elongation, from $10 \%$ to $16 \%$ shown as in Fig.5. The elongation of the quenched specimen heated by resistance heating significantly increased by $60 \%$ and the ultra tensile strength (UTS) also increased from $1496 \mathrm{MPa}$ to $1573 \mathrm{MPa}$. The elongation of the boron steel was increased with no expense of strength.

The improvement in mechanical properties is probably attributed to refined martensite. Since the refined martensite hinders dislocation movement and makes it more difficult to slip, the UTS of the specimen is increased. In addition, the refined martensite reduces the stress concentration of the interface so that the material can withstand larger 
deformation before breaking. That is the reason for the improved elongation of the specimen.

\section{Hardness measurements}

As is shown in Fig.6, hardness values in resistance heating ranged from approximately $480 \mathrm{HV}$ to $510 \mathrm{HV}$, while in the condition of using furnace heating, hardness values varied in the range between $470 \mathrm{HV}$ and $500 \mathrm{HV}$. The hardness measurements indicated a fully hardened martensitic microstructure. In contrast to furnace heating, resistance heating produced higher hardness values.

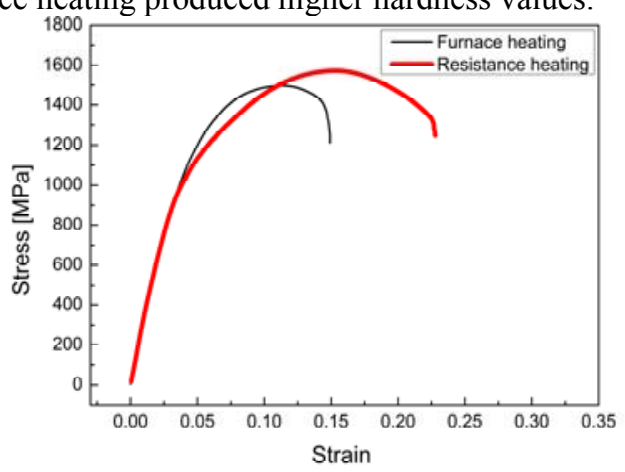

Figure 5. Engineering stress versus strain of quenched blanks heated bv resistance heating and furnace heating.

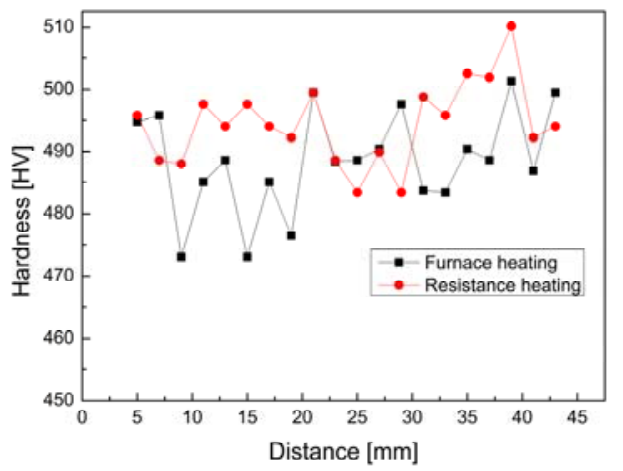

Figure 6. Lateral hardness profiles of quenched specimens heated by resistance heating and furnace heating.

There are fluctuations in lateral hardness of quenched specimens. Non-uniform distribution of carbon in martensite which is caused by non-uniform distribution of carbon in primary austenite may lead to the hardness violations. An increase in carbon content of a local region of primary austenite improves distortion of body center tetragonal (BCT) lattice during martensite formation and decreases the movement of dislocations in that region and therefore hardness value increases.

\section{Metallographic analysis results}

The microstructures of quenched specimens heated by resistance heating and furnace heating are shown in Fig.7. Quenched blanks at cooling speed of $150^{\circ} \mathrm{C} / \mathrm{s}$ had fully martensitic microstructure in resistance heating and furnace heating. The metallographic analysis results are in accordance with the hardness measurements. Because the weight percent carbon of the boron steel is less than $0.60 \%$, the as-quenched martensite consists of a lath structure [9]. In contrast to the furnace heating, resistance heating produces more refined marensite grains.
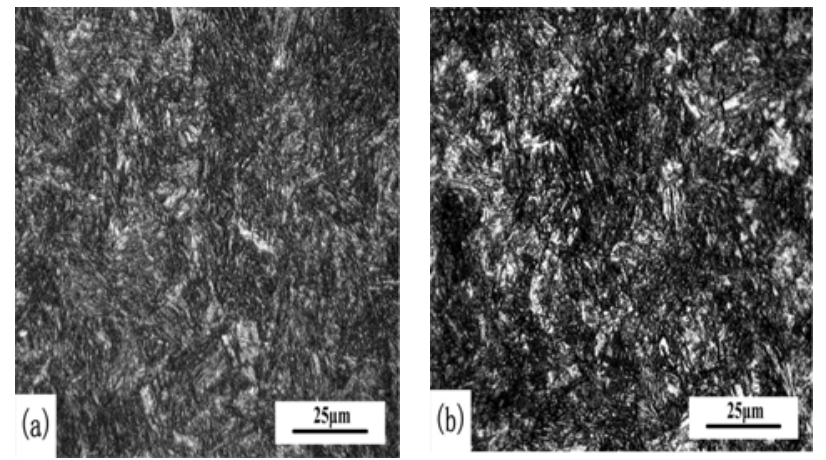

Figure 7. Optical micrographs of quenched specimens (a) resistance heating (b) furnace heating.

The grain size of martensite depends on the grain size of the high temperature austenite which is affected by heating process. The formation of austenite includes the nucleation and growth processes which are controlled by atomic diffusion. Therefore, all influencing factors of diffusion, nucleation and growth will affect the austenization process. When austenite phase change occurs, the atomic diffusion may be influenced by pulse current, resulting in the reduction of diffusion activation energy for carbon and iron atoms and the improvement of intrinsic diffusion coefficient. Thus the austenization process is promoted. Moreover, the grain has no enough time to grow by rapid resistance heating and the final grain size mainly depends on the nucleation rate. The nucleation rate of austenite significantly increases and tiny grains of austenite are obtained when the pulse current is applied and therefore the tiny grain of austenite will get the tiny grain of martensite.

\section{CONCLUSIONS}

The relationship between heating time and temperature showed a linear trendline. For boron steel with $1.5 \mathrm{~mm}$ thickness, it only needed 1.4 seconds to get $950^{\circ} \mathrm{C}$. Because of high speed heating, resistance heating can synchronize with a press. The elongation of the quenched specimen heated by resistance heating significantly increased by $60 \%$ and the UTS also increased from $1496 \mathrm{MPa}$ to $1573 \mathrm{MPa}$. The elongation of the boron steel was increased with no expense of strength. Hardness values in resistance heating ranged from approximately $480 \mathrm{HV}$ to $510 \mathrm{HV}$, while in the condition of using furnace heating, hardness values varied in the range between $470 \mathrm{HV}$ and $500 \mathrm{HV}$. In contrast to furnace heating, resistance heating produced higher hardness values. Quenched blanks at cooling speed of $150^{\circ} \mathrm{C} / \mathrm{s}$ had fully martensitic microstructure in resistance heating and furnace heating. In contrast to the furnace heating, resistance heating produced more refined martensite grains. 


\section{ACKNOWLEDGMENTS}

This work was supported by National Natural Science Foundation of China (No. 51205162) and (No. 51275203).

\section{REFERENCES}

[1] A. Bardelcik, C. Salisbury, S. Winkler, M.A. Wells and M.J. Worswick: Int J. Impact Eng Vol. 37 (2010), p. 694

[2] K. Mori, S. Maki and Y. Tanaka: Annals of the CIRP Vol. 54 (2005), p.209

[3] K. Mori, S. Saito and S. Maki: Annals of the CIRP Vol. 57 (2008), p. 321
[4] K. Mori, T. Maeno and Y. Fukui: Annals of the CIRP Vol. 60 (2011), p.299

[5] K. Mori, T. Maeno and S. Fuzisaka: J Mater Process Technol Vol. 212(2) (2012), p.534.

[6] K. Mori, T. Maeno and Y. Maruo: Annals of the CIRP Vol. 61 (2012), p. 255

[7] K. Mori, T. Maeno and K. Mongkolkaji: J Mater Process Technol Vol. 213(3) (2013), p.508

[8] Y.G. Zhao, B.D. Ma, H.C. Guo, J. Ma, Q. Yang and J.S. Song: Mater Design Vol. 43 (2013), p. 195

[9] A.R. Marder and G. Krauss: Asm Transactions Quarterly Vol. 60(4) (1967), p.651 